Yüzüncü Y1 Üniversitesi
Tarim Bilimleri Dergisi

Araştırma Makalesi (Research Article)

\title{
Bă̆ ve Elma Bahçelerinde Toprak Agregasyonunun Değerlendirilmesi
}

\author{
Metin MÜJDECi' ${ }^{1}$, Pelin ALABOZ ${ }^{2 *}$, Ahmet Ali IŞILDAR ${ }^{3}$, Veli UYGUR ${ }^{4}$ \\ 1,2,3,4 Isparta Uygulamalı Bilimler Üniversitesi, Ziraat Fakültesi, Toprak Bilimi ve Bitki Besleme Bölümü, 32200 , \\ Isparta, Türkiye \\ ${ }^{1}$ https://orcid.org/0000-0002-0579-4538 ²https://orcid.org/ 0000-0001-7345-938X 3https://orcid.org/ 0000-0001-7099-8011 \\ ${ }^{4}$ https://orcid.org/0000-0003-3971-7714 \\ *Sorumlu yazar e-posta:pelinalaboz@isparta.edu.tr
}

\section{Makale Bilgileri}

Geliş: 03.02.2020

Kabul: 11.05 .2020

Online Yayınlanma 30.09.2020

DOI: 10.29133/yyutbd.684270

\section{Anahtar kelimeler}

Agregat stabilitesi,

Bağ,

Elma bahçesi.
Öz: Agregat oluşumu ve stabilitesi; toprak yönetimine ilişkin kültivasyon uygulamaları ve bitkisel üretim farklılıklarından güçlü bir şekilde etkilenmektedir. Bu çalışmada; farklı bitki örtüsü koşullarının (elma bahçesi ve bağ) toprakların agregasyon yüzdelerinde nasıl bir değişim gösterdiği araştırılmıştır. Elma bahçesi ve bağdan $(0-10,10-20 \mathrm{~cm})$ alınan toprak örnekleri farklı agregat boyutlarına $(8-4,4-2,2-1,<1 \mathrm{~mm})$ ayrılarak söz konusu toprakların agregasyon yüzdeleri belirlenmiştir. Agregasyon yüzdesi her bir derinlikte bitki örtüsüne bağlı değişim göstermekte olup bu değişim istatistiksel olarak önemli bulunmuştur $(\mathrm{P}<0.01)$. Agregasyon yüzdesi bitki türüne bakılmaksızın en yüksek 0-10 cm derinliğinde (62.32 (elma bahçesi), 61.14 (bağ)) belirlenmiş̧tir. Agregat boyutlarındaki agregasyon \%59.44 (2-1 mm)-\%63.78 (8-4 mm) arasında değişim göstermiş olup elma bahçesinin agregasyon yüzdeleri bağa göre daha yüksek bulunmuştur. Sonuç olarak, bitki türü organik madde birikimini etkilediği için toprakların agregasyonlarını değiştirebilmektedir.

\section{Assessment of Soil Aggregation in the Vineyards and Apple Orchard}

\section{Article Info}

Received: 03.02.2020

Accepted: 11.05.2020

Online Published 30.09.2020

DOI: $10.29133 /$ yyutbd.684270

\section{Keywords}

Aggregate stability,

Vineyard,

Apple orchard.

\begin{abstract}
Aggregate formation and stability are strongly influenced by cultivation practices related to soil management and plant type. The aim of this study was to investigate how different plant type (apple orchard and vineyard) have influenced the soil aggregation percentages. The soil samples taken from an apple orchard and a vineyard at different depths $(0-10,10-20 \mathrm{~cm})$ were divided into different aggregate sizes (8-4, 4-2, 2-1, <1 mm) then the percentages of soil aggregation were determined. The magnitude of aggregation percentage was siteand depth-dependent and these changes were statistically significant $(\mathrm{P}<0.01)$. The highest percentage of aggregation was found (62.32 for apple orchard, 61.14 for vineyard) at $0-10 \mathrm{~cm}$ depth regardless of plant type. The aggregation percentage was highly aggregate size-dependent. It was related to aggregate size i.e. $59.44 \%$ for $2-1 \mathrm{~mm}$ and $63.78 \%$ for $8-4 \mathrm{~mm}$ sized aggregates. Comparatively higher aggregation percentages were observed for apple orchard soil than the ones observed for vineyard soil. As a consequence, plant type may change soil aggregation due possibly to influence over organic matter turnover.
\end{abstract}

\section{Giriş}

Ekosistemin önemli bir parçası olan toprağın amaç dışı kullanımı üretim alanlarının azalmasına yol açmakta, artan nüfusun ihtiyacının karşılanması için yoğun girdi kullanımı ile birim alandan daha 
yüksek üretim yapılmasını zorunlu kılmaktadır. Bitki gelişimi üzerine toprağın kimyasal özelliklerinin etkinliği daha ön planda düşünülse de, tüm özellikleri ile bir bütün olan toprağın fiziksel özellikleri de verimlilik ve kalite için oldukça önemlidir. Kimyasal ve biyolojik özellikleri optimum düzeyde olan bir toprağın zayıf fiziksel özellikleri, bitkisel üretim potansiyelini sınırlandırmaktadır. Bitkiler için büyüme faktörü olmayan toprak strüktürü, dolaylı olarak bitki büyümesi ile yakından ilgilidir. Toprakta su ve hava hareketi, su tutma ve havalanma kapasitesi, bitki besin maddelerinin yarayışl11lğı, bitki kök gelişimi, makro ve mikro organizma aktivitesi gibi özellikler toprak strüktürü ile ilişkilidir. Uygun toprak strüktürü ve yüksek agregat stabilitesi bitkisel üretim, sürdürülebilir toprak yönetimi ve erozyona dayanıklılık açısından oldukça önemlidir (Bronick ve Lal, 2005; Alagöz ve Yılmaz, 2009; Turgut ve Aksakal, 2010; Eraslan ve ark., 2016). Universal Toprak Kayıp Tahmini Eşitliğinde (USLE) kullanılan erozyona duyarlılık $(\mathrm{K})$ faktörü belirlemesinde de strüktürel özelliklerden yararlanılmaktadır. Toprak kaybının azaltılması için $\mathrm{K}$ değerlerinin en düşük düzeyde tutulması ve strüktürün iyileştirilmesi gerekmektedir (Cebel ve ark., 2013). Strüktürel bakımdan sağlam yapılı topraklarda suyun dispers edici etkisine karşı agregatların stabiliteleri de yüksek olacağından bu topraklarda erozyona karşı duyarlılık derecesi de azalmaktadır (Karaman ve ark., 2007).

Doğal koşullar altında uygun strüktür yapısına sahip arazilerde, sık ve yoğun kültivasyon çoğu toprakların strüktürünü bozmaktadır (Veiga ve ark., 2009). Bunun yanında, iklim koşulları (yıllık ortalama yağış ve yıllık ortalama sıcaklık vb.) vejetasyon türleri (orman arazisi, çim arazi ve ürün arazileri vb.), toprak işleme yöntemleri, sulama ve gübre uygulamaları gibi tarımsal faaliyetler de toprakların agregat oluşumu ve stabilitesini etkilemektedir (Işı1dar, 1999; Castro Filho ve ark., 2002; Annabi ve ark., 2011).

Toprak agregasyonunun oluşumunda; organik karbon, organizmalar, iyon köprüleri, kil ve karbonatlar (Bronick ve Lal, 2005) etkili özellikler arasındadır. Toprak agregasyonunda önemli bir yeri olan toprak organik maddesinin \%48-58'ini karbon (C) oluşturmaktadır (Kacar, 2009). Farklı toprak işleme yöntemlerine bağlı olarak değişim gösteren organik karbon, sıfır sürüm uygulamalarında, daha yüksek seviyelerde (Six ve ark., 2002; Kumar ve ark., 2012; Kumar ve ark., 2014) bulunmaktadır. Ayrıca, farklı bitki örtüleri, toprak organik madde içeriğini etkileyerek, toprak agregat oluşumu ve stabilitesi üzerinde önemli katkılar (Zeng ve ark., 2018) sağlamakta olup organik materyal uygulamaları (Yılmaz ve Alagöz., 2005; Alaboz ve ark., 2017) ve farklı toprak yönetimleri (Nweke ve Nnabude, 2014) ile agregat boyutlarında değişimlerin olduğu bilinmektedir.

Bu çalışmada; farklı bitki örtüsü koşullarında (elma bahçesi, bağ) toprakların farklı agregat boyutlarındaki (8-4, 4-2, 2-1, <1 mm) agregasyon yüzdeleri araştırılmıştır.

\section{Materyal ve Yöntem}

Araştırma, Süleyman Demirel Üniversitesi Tarımsal Araştırma ve Uygulama Merkezi arazisinde [36282989-36283041 D ve 4190610-4190784 K (UTM 36)] bulunan yaklaşık 9 yaşlarındaki elma bahçesi (M9 anac1) ve üzüm bağı arazilerinin toprakları üzerinde yürütülmüştür (Şekil 1). Bölgede yarı kurak iklim tipi hakimdir. Çalışma alanının uzun yıllar (1929-2018) meteorolojik verilerine göre (MGM, 2020), yıllık ortalama sıcaklık $12.5^{\circ} \mathrm{C}$, yăğı̧ ise $564 \mathrm{~mm}$ 'dir. Jeolojik yapı kretese kireç taşlarından oluşmakta olup, toprak nem rejimi xeric, sıcaklık rejimi ise mesic'tir (Akgül ve Başayiğit, 2005).

Çalışma alanı, her yıl çizel ve çapayla $(10-15 \mathrm{~cm})$ işlenmiştir. Çalışmanın amacı kapsamında, aynı hat üzerinde bulunan elma bahçesi ve bağ topraklarından (0-10 ve $10-20 \mathrm{~cm})$ aynı hat üzerinden her bir tekerrür için 5 noktadan olmak üzere 3 tekerrürlü olarak toprak örnekleri alınmış (13.08.2014) ve analizler 3 paralelli olarak yapılmıştır. Araziden alınan toprak örnekleri, laboratuvarda hava kuru hale getirilerek elle agregat yapısına zarar vermeyecek şekilde $8 \mathrm{~mm}$ 'lik elekten geçecek büyüklüğe getirilmiştir. Topraklar 1slak-kuru eleme seti (Retch Model: AS 200) yardımıyla 8-4 mm, 4-2 mm, 2-1 $\mathrm{mm},<1 \mathrm{~mm}$ 'lik kuru agregat büyüklük gruplarına ayrılmıştır. Eleme işlemi, $1000 \mathrm{~g}$ toprak kullanılarak, 80 amplitüt ve 30 saniye eleme süresince gerçekleştirilmiştir. Elenen her bir agregat büyüklük boyutu için agregasyon yüzdeleri Eşitlik 1'e göre belirlenmiştir (US Salinity Laboratory Staff, 1954).

$$
\% \text { Agregasyon }=\frac{(\text { Toplam } \% \text { silt }+ \text { kil })-(\text { Bağlanmamış } \% \text { silt }+ \text { kil }) * 100}{\text { Toplam } \% \text { silt }+ \text { kil }} \quad \text { Eşitlik } 1
$$




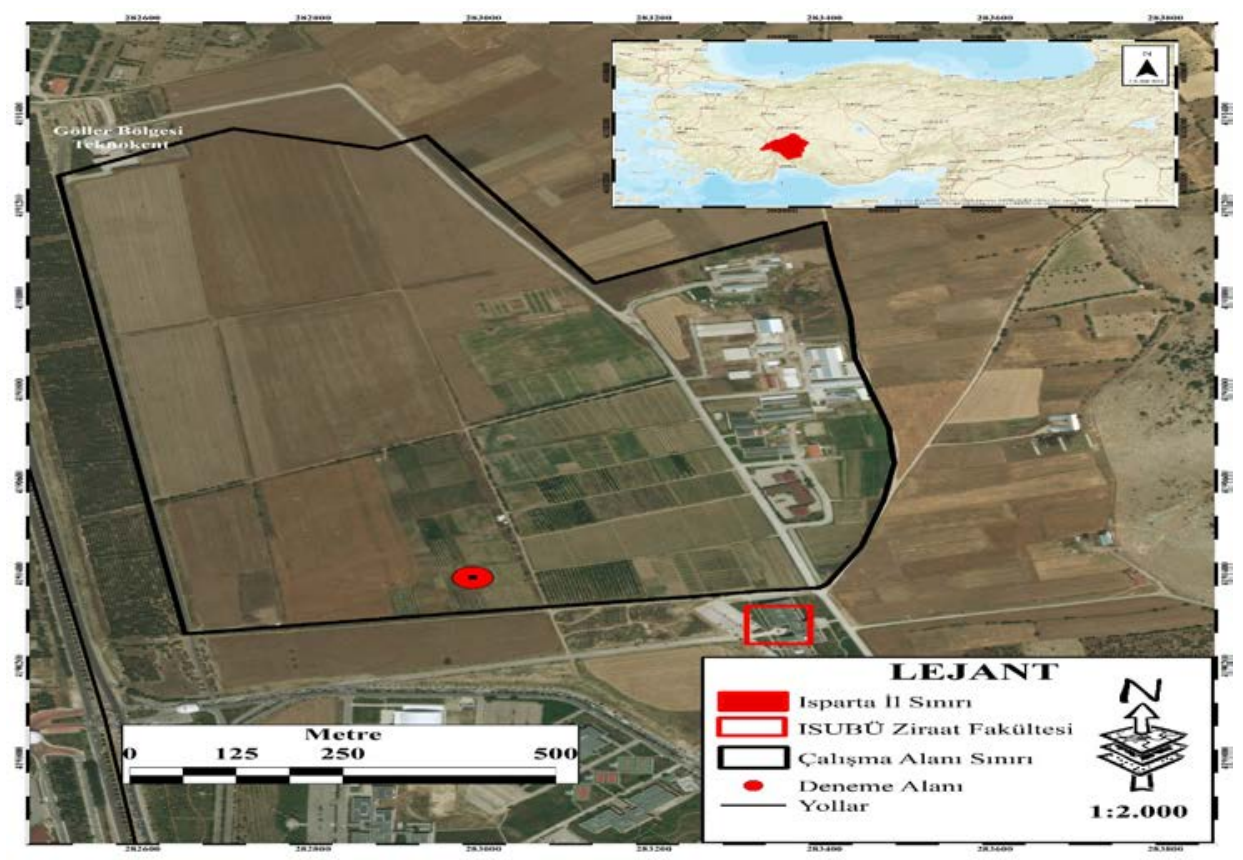

Şekil 1. Çalışma alanı

Toprakların, mekanik analizi Bouyoucos hidrometre yöntemiyle (Demiralay, 1993), pH ve elektriksel iletkenlik (EC) 1:1 toprak-su süspansiyonunda (US Salinity Labortory Staff, 1954), organik madde değiştirilmiş Walkey-Black yöntemi ve $\mathrm{CaCO}_{3}$, Scheibler kalsimetresi ile volumetrik olarak belirlenmiştir (Kacar, 2009). Verilerin istatistiksel analizlerinde Minitab-16 paket programından yararlanılarak Tukey çoklu karşılaştırma testi kullanılmıştır.

\section{Bulgular ve Tartışma}

Deneme alanı topraklarının bazı fiziksel ve kimyasal özellikleri Çizelge 1'de verilmiştir. Toprakların tekstür sınıfı her iki bitki örtüsü ve derinlikte tın olarak belirlenmiş olup \% kil, silt ve kum içerikleri birbirine oldukça yakın seviyelerdedir. Toprakların $\mathrm{CaCO}_{3}$ içerikleri çok yüksek seviyelerde belirlenmiştir (Kacar, 2009). Elma bahçesi topraklarının $\mathrm{CaCO}_{3}$ içerikleri bağ'a göre yaklaşık \% 9 daha yüksektir. Toprakların organik madde içerikleri düşük (Ülgen ve Yurtsever, 1988), toprak reaksiyonu hafif alkali (Jones, 1984), EC değerleri ise tuzsuz (Dahnke ve Whitney, 1988) sinıfları içerisinde yer almaktadır. Belirlenen toprak özellikleri arasında yüzey toprağında nispeten daha yüksek olan organik madde ve EC içerikleri derinliğe bağlı olarak azalmıştır. Gerek bitki artıklarının yüzeyde olması gerek organik veya mineral gübrelerin yüzeye uygulanması söz konusu derinlik $(0-10 \mathrm{~cm})$ için yüksekliğin bir sebebidir. Belirlenen toprak özellikleri bölgede Akgül ve Başayiğit (2005) tarafindan yapılan çalışmayla uyumlu bulunmuştur.

Çizelge 1. Deneme alanı topraklarının bazı fiziksel ve kimyasal özellikleri

\begin{tabular}{|c|c|c|c|c|c|c|c|c|c|}
\hline $\begin{array}{c}\text { Bitki } \\
\text { Örtüsü }\end{array}$ & $\begin{array}{c}\text { Derinlik } \\
(\mathrm{cm})\end{array}$ & $\begin{array}{l}\text { Kil } \\
(\%)\end{array}$ & $\begin{array}{l}\text { Silt } \\
(\%)\end{array}$ & $\begin{array}{c}\text { Kum } \\
(\%)\end{array}$ & $\begin{array}{c}\text { Tekstür } \\
\text { sinıfi }\end{array}$ & $\begin{array}{c}\mathrm{CaCO}_{3} \\
(\%) \\
\end{array}$ & $\begin{array}{c}\text { Organik } \\
\text { Madde } \\
(\%)\end{array}$ & $\mathrm{pH}$ & $\begin{array}{c}\mathrm{EC} \\
\left(\mathrm{dS} \mathrm{m}^{-1}\right)\end{array}$ \\
\hline \multirow{2}{*}{ Bağ } & $0-10$ & 23.71 & 34.24 & 42.05 & $\mathrm{~L}$ & 28.71 & 1.30 & 7.52 & 0.28 \\
\hline & $10-20$ & 24.33 & 34.19 & 41.48 & $\mathrm{~L}$ & 28.46 & 1.21 & 7.58 & 0.17 \\
\hline \multirow{2}{*}{ Elma Bahçesi } & $0-10$ & 23.65 & 34.82 & 41.53 & $\mathrm{~L}$ & 36.93 & 1.54 & 7.51 & 0.22 \\
\hline & $10-20$ & 25.15 & 34.04 & 40.82 & $\mathrm{~L}$ & 36.72 & 1.28 & 7.55 & 0.15 \\
\hline
\end{tabular}

Toprakların minimum ve maksimum agregasyon yüzdesi değerleri \% 58.39 ve \% 65.03'dir. Veri setinin standart hatas 1.812 , varyasyon katsayıs1 2.96 , çarpıklığ 1 ise 0.51 'dir. Veri seti normal bir dağılım sergilemiştir. Farklı bitki örtüsü koşullarının derinlik ve agregat büyüklük farklılığına bağlı olarak agregasyon yüzdesi üzerine değişimi Çizelge 2' de belirtilmiştir. Agregasyon yüzdesi bağ' da \% 58.45-63.76, elma bahçesinde ise \% 59.56-64.97 arasında belirlenmiştir. Derinliğe bağl1 değişimin agregasyon üzerine etkisi istatistiksel anlamda önemli olup $(\mathrm{P}<0.01)$ en yüksek yüzey toprağında $(0-10$ 
$\mathrm{cm}$ ) belirlenmiştir (\% 61.73 ). Bunun sebebinin yüzeyde organik madde miktarının (Çizelge 1) 10-20 cm’ye göre daha yüksek olmasından kaynaklandığı düşünülmektedir. Organik maddenin parçalanıp ayrışmasıyla yapıştırıcı, kümeleştirici etkisi artmakta olup organik materyal uygulamasıyla agregat stabilitesinde artışların olduğu literatürlerde de belirtilmiştir (Lehtinen ve ark., 2014). Elliott (1986) organik maddenin bağlayıcı görevinde olduğunu küçük agregat gruplarının büyük agregat boyutlarını oluşturabileceğine değinmektedir. Organik materyalin yüzey toprağında agregat oluşumu üzerinde etki sahibi olduğu ve ahır gübresi gibi materyallerin $\mathrm{C} / \mathrm{N}$ oranlarının yüksek olması sebebiyle ayrışmanın geç olmasından kaynaklı etkinin daha uzun sürelerde ortaya çıkabileceği belirtilmektedir (Çaliskan ve ark., 1997). Bitki örtüsü farklılıkları dikkate alınmaksızın farklı agregat boyutlarındaki agregasyon, en yüksek \% 63.78 ile 8-4 mm agregat boyutunda belirlenmiştir. Agregat boyutlarının küçülmesine bağlı olarak agregasyon oranında olan azalış istatistiksel olarak önemli seviyelerde $(\mathrm{P}<0.01)$ bulunmuştur.

Çizelge 2. Farklı bitki örtüsü koşullarının derinlik ve agregat boyutuna bağlı olarak agregasyon yüzdesi üzerine etkileri

\begin{tabular}{|c|c|c|c|c|c|c|c|}
\hline \multirow{2}{*}{ Bitki örtüsü } & \multirow{2}{*}{$\begin{array}{l}\text { Derinlik } \\
\text { (cm) }\end{array}$} & \multicolumn{4}{|c|}{ Agregat Boyutu (mm) } & \multirow{2}{*}{$\begin{array}{l}\text { Derinlik } \\
(\mathrm{cm})\end{array}$} & \multirow[b]{2}{*}{ Ortalama } \\
\hline & & $8-4$ & $4-2$ & $2-1$ & $<1$ & & \\
\hline \multirow{2}{*}{$\mathrm{Bağ}$} & $0-10$ & 63.76 & 61.46 & 59.25 & 60.10 & \multirow{2}{*}{$0-10$} & \multirow[b]{2}{*}{$61.73 a^{* *}$} \\
\hline & $10-20$ & 62.71 & 60.35 & 58.45 & 59.43 & & \\
\hline \multirow{3}{*}{ Elma bahçesi } & $0-10$ & 64.97 & 62.57 & 60.51 & 61.21 & \multirow{2}{*}{$10-20$} & \multirow{2}{*}{$60.74 b$} \\
\hline & $10-20$ & 63.67 & 61.36 & 59.56 & 60.36 & & \\
\hline & Ortalama & $63.78 A^{*}$ & $61.43 \mathrm{~B}$ & 59.44D & $60.28 \mathrm{C}$ & & \\
\hline
\end{tabular}

*Büyük harfler agregat boyutları arasındaki değişimi göstermektedir $(\mathrm{P}<0.01)$.

**Küçük harfler derinlikler arasındaki değişimi göstermektedir( $\mathrm{P}<0.01)$.

Derinliğe bağlı agregasyon boyutlarındaki \% agregasyon değişimi istatistiksel olarak önemli bulunmuş olup Çizelge 3'de belirtilmiştir. En yüksek 0-10 cm'de 8-4 mm agregat boyutunda (\% 64.36) en düşük ise 10-20cm'de 2-1 mm agregat boyutunda (\% 59.01) belirlenmiştir. Özdemir ve Canbolat (1997), toprakta 1-10 mm arasındaki suya dayanıklı agregateların bulunmasıyla bitki gelişimi için uygun bir ortamın olacağını belirtmişlerdir. Genel olarak derinliğe bağlı olarak tüm agregat boyutlarında bir azalmanın olduğu görülmektedir. Bu azalma, toprağın organik madde içeriği, agregasyon oluşturucu katyonların varlığı ya da biyolojik etkenlerin farklılığı gibi birçok faktörün etkisi altında değişim göstermiş olabilmektedir. 2-1 mm agregat boyutuna kadar boyut küçüldükçe agregasyonda da azalış gözlenirken $<1 \mathrm{~mm}$ boyutunda azda olsa bir artış gözlenmiştir. Bu artışın kil fraksiyonlarının $<1 \mathrm{~mm}$ boyutunda ki agregat gruplarında daha fazla miktarda olabileceğinden kaynaklanabilmektedir. Kil miktarının artışıla birlikte agregat stabilitesinde de artışlar görülmektedir (Yılmaz ve ark., 2005). Negatif yüklü kil tanecikleri suyun dipolar özelliği sayesinde bir araya gelerek flokülasyona neden olmaktadır. Böylelikle yüksek kil içeriği yüksek agregasyona neden olabilmektedir (Nimmo, 2004).

Çizelge 3. Derinliğe bağlı agregat boyutlarındaki değişimin agregasyon (\%) üzerine etkisi

\begin{tabular}{ccccc}
\hline & \multicolumn{4}{c}{ Agregat Boyutu (mm) } \\
\hline Derinlik $(\mathrm{cm})$ & $8-4$ & $4-2$ & $2-1$ & $<1$ \\
\hline $0-10$ & $64.36 a$ & $62.01 c$ & $59.88 f$ & $60.66 e$ \\
$10-20$ & $63.19 b$ & $60.85 d$ & $59.01 \mathrm{~g}$ & $59.90 f$ \\
& & & \\
\hline Derinlik* Agregat boyutu & $\mathrm{P}$ & & $\mathrm{F}$ & \\
\hline
\end{tabular}

Farklı bitki örtüsü koşullarının derinliğe bağlı değişiminin agregasyon üzerine etkisi Çizelge 4'de belirtilmiş olup söz konusu değişim istatistiki olarak önemli seviyede belirlenmiştir $(\mathrm{P}<0.01)$. Agregasyon yüzdesi en düşük (60.24) 10-20cm derinlikte bağ' da, en yüksek ise (62.32) 0-10cm'de elma bahçesinde görülmektedir. Elma bahçesinde bağ'a göre agregasyon yüzdesi daha yüksek belirlenmiş olup bunun sebebinin bağ'a göre elma bahçesinde daha yüksek organik madde ve kireç (Çizelge 1) kaynaklı olmasının yanında diğer kimyasal ve biyolojik etkenler olabilmektedir. Agregatlaşmayı etkileyen diğer bir önemli faktörün toprakların $\mathrm{CaCO}_{3}$ içeriği olduğunu belirten Yılmaz ve ark. (2005), Ca doygunluğunun yüksek olması, kolloidler arasındaki bağı ve biyolojik aktiviteyi arttırarak stabiliteyi de etkilediğini bildirmiştir (Özbek ve ark., 1995). Ayrıca söz konusu bitki örtüsü koşullarının her birinin kök sistemlerinin farklı olması ve kılcal köklerinde agregasyon üzerinde etkili bir faktör olduğu 
düşünülürse bu farklılığın ortaya çıkması beklenen bir durumdur. Söz konusu bitki yönetimlerinde, aynı tip toprak işleme olsa da gerek kök yapısındaki farklılık gerek toprakların bazı kimyasal özelliklerindeki değişimler agregasyon üzerinde etkilidir. Özdemir ve Canbolat (1997) tarafından agregatların stabilitesini; bitki yönetimi, gübreleme, drenaj ile sulama suyu kalitesi gibi parametrelerin etkileyeceğini, mikro agregatların oluşmasında organo-mineral kompleksleri ile polisakkaritlerin, makro agregatların oluşumunda ve stabilitesinde ise bitki kökleri, bakteri ve mantar misellerinin oldukça etkili olduğu bildirilmiştir.

Çizelge 4. Farklı bitki örtüsü koşullarının farklı derinliklerde agregasyon (\%) üzerine etkisi

\begin{tabular}{ccc}
\hline Derinlik $(\mathrm{cm})$ & Bă & Elma \\
\hline $0-10$ & $61.14 \mathrm{~b}$ & $62.32 \mathrm{a}$ \\
$10-20$ & $60.24 \mathrm{c}$ & $61.24 \mathrm{~b}$ \\
& Varyasyon Kaynakları & $\mathrm{F}$ \\
\hline Derinlik*Bitki örtüsü & $\mathrm{P}$ & 12.07 \\
\hline
\end{tabular}

\section{Sonuçlar}

Farklı bitki örtüsü koşullarının (elma bahçesi, bağ) toprak agregasyonu üzerine etkisinin araştırıldığ 1 bu çalışmada; söz konusu bahçelerden $(0-10,10-20 \mathrm{~cm})$ alınan örnekler agregat boyutlarına (8-4, 4-2, 2-1, <1 mm) ayrılarak toprakların agregasyon yüzdeleri belirlenmiştir.

Agregasyon yüzdesi her bir derinlikte bitki örtüsüne bağlı olarak değişim göstermekte olup, bağ'a göre elma bahçesinin agregasyon yüzdelerinin daha yüksek olduğu ve bunun sonucu farklı bitki örtüsü koşullarında toprakların agregasyonlarında değişimlerin olacağı belirlenmiştir. Ayrıca yüzey toprağının $(0-10 \mathrm{~cm})$ organik madde içeriğinin yüksek olması agregasyon yüzdesinde artışların bir sebebi olabileceği düşünülmektedir. Çalışma sonucunda daha net bilgilerin elde edilebilmesi adına farklı toprak yönetim ve bitki örtüsü koşullarında, uzun süreli ve agregasyonu etkileyen diğer parametrelerin incelendiği bir çalışmanın yürütülmesi önerilmektedir.

\section{Teșekkür}

$\mathrm{Bu}$ çalışma " 3 rd International Conference on Science, Ecology and Technology (14-16 August, 2017, Rome-Italy)” isimli konferansta sunulmuş ve özet metin olarak basılmıştır.

\section{Kaynaklar}

Akgül, M., \& Başyiğit, L. (2005). Süleyman demirel üniversitesi çiftlik arazisinin detaylı toprak etüdü ve haritalanması. Süleyman Demirel Üniversitesi Fen Bilimleri Enstitüsü Dergisi, 9(3), 1-10.

Alaboz, P., Işı1dar, A.A., Müjdeci, M., \& Şenol, H. (2017). Effects of different vermicompost and soil moisture levels on pepper (capsicum annuum) grown and some soil properties. Yüzüncü Yıl Üniversitesi Tarım Bilimleri Dergisi, 27(1), 30-36.

Alagöz, Z., \& Yilmaz, E. (2009). Effects of different sources of organic matter on soil aggregate formation and stability: a laboratory study on a lithic rhodoxeralf from Turkey. Soil and Tillage Research, 103(2), 419-424.

Annabi, M., Le Bissonnais, Y., Le Villio-Poitrenaud, M., \& Houot, S. (2011). Improvement of soil aggregate stability by repeated applications of organic amendments to a cultivated silty loam soil. Agriculture, Ecosystems \& Environment, 144(1), 382-389.

Bronick, C. J., \& Lal, R. (2005). Manuring and rotation effects on soil organic carbon concentration for different aggregate size fractions on two soils in northeastern Ohio USA. Soil \& Tillage Research, 81, 239-252.

Castro Filho, C. D., Lourenço, A., Guimarães, M. D. F., \& Fonseca, I. C. B. (2002). Aggregate stability under different soil management systems in a red latosol in the state of parana, Brazil. Soil \& Tillage Research, 65(1), 45-51.

Cebel, H., Suat Akgül, S., Doğan, O., \& Elbaşı, F. (2013). Türkiye Büyük Toprak Gruplarının Erozyona Duyarl111k "K" Faktörleri. Toprak Su Dergisi, 2(1), 30-45.

Çaliskan, N., Koç, N., Kaya, A., \& Senses, T. (1997). Compost Productıon from Hazelnut Husk. Acta Horticulturae, (445), 279-284. 
Dahnke, W. C., \& Whitney, D. A. (1988). Measurement of soil salinity. Recommended Chemical Soil Test Procedures for The North Central Region, 221, 32-34.

Demiralay, İ. (1993). Toprak Fiziksel Analizleri. A.Ü. Ziraat Fakültesi Yayınları, 143s, Erzurum.

Elliott, E.T. (1986). Aggregate structure and carbon, nitrogen and phosphorus in native and cultivated soils. Soil Science Society of America Journal, 50(3), 627-633.

Eraslan, S., İmamoğlu, A., Coşkun, A., Saygın, F., \& Dengiz, O. (2016). İnebolu Havzası topraklarının erozyon duyarlılıklarını belirlenmesinde agregat ve strüktür stabilite durumları, Arazi örtüsü ile olan ilişkileri. Uluslararası Coğrafya Sempozyumu, 13-14.

Işıldar, A. 1999. Farklı bitki örtüsü koşullarının toprakların erozyona duyarlılığı üzerine etkileri. Turkish Journal of Agriculture and Forestry, (3), 665-670.

Jones Jr, J. B. (1984). A laboratory guide of exercises in conducting soil test, and plant analyses. No. 631, 4246.

Kacar, B., (2009). Toprak Analizleri. Nobel Yayın Dağıtım, 467s, Ankara.

Karaman, M. R., Brohi, A. R., Müftüoğlu, N. M., Öztaş. T., \& Zengin, M. (2007). Sürdürülebilir Toprak Verimliliği. Detay Yayıncılık, Ankara.

Kumar, S., Kadono, A., Lal, R., \& Dick, W. (2012). Long-term no-till impacts on organic carbon and properties of two contrasting soils and corn yields in Ohio. Soil Science Society of America Journal, 76(5), 1798-1809.

Kumar, S., Nakajima, T., Mbonimpa, E. G., Gautam, S., Somireddy, U. R., Kadono, A., \& Fausey, N. (2014). Long-term tillage and drainage influences on soil organic carbon dynamics, aggregate stability and corn yield. Soil Science and Plant Nutrition, 60(1), 108-118.

Lehtinen, T., Schlatter, N., Baumgarten, A., Bechini, L., Krüger, J., Grignani, C., Zavattaro, L., Costamagna, C., \& Spiegel, H. (2014). Effect of crop residue incorporation on soil organic carbon and greenhouse gas emissions in european agricultural soils. Soil Use and Management, 30(4), 524-538.

Meteoroloji Genel Müdürlüğü (MGM). (2020). http://www. mgm.gov.tr/veridegerlendirme/yilliktoplam-yagis verileri .aspx \#sfU. Erişim tarihi: 09.04.2020.

Nimmo, J. R. (2004). Porosity and pore size distribution. In: D Hillel (Eds.), Encyclopedia of Soils In The Environment. Elsevier, 3, 295-303, London UK,

Nweke, I. A., \& Nnabude, P. C. (2014). Aggregate size distribution and stability of aggregate fraction of fallow and cultivated soils. Journal of Experimental Biology and Agri. S., 1(5), 14-20.

Özbek, H., Kaya, Z., Gök, M., \& Kaptan, H. (1995). Toprak Bilimi. Çukurova Üniversitesi Ziraat Fakültesi Genel Yayın, 73, Adana.

Özdemir, N., \& Canbolat, M.Y., (1997). Toprak strüktürünün oluşum süreçleri ve yönetimi. Atatürk Üniversitesi Ziraat Fakültesi Dergisi, 28(3), 413-419.

Six, J., Feller, C., Denef, K., Ogle, S., De Moraes Sa, J. C., \& Albrecht, A. (2002). Soil organic matter, biota and aggregation in temperate and tropical soils-effects of no tillage. Agronomy, 22(7-8), 755-775.

Turgut, B., \& Aksakal, E. L. (2010). Fiğ samanı ve ahır gübresi uygulamalarının toprak aşınım parametreleri üzerine etkileri. Artvin Çoruh University Faculty of Forestry J., 11(1), 1-10.

U.S Salinity Laboratory Staff (1954). Diagnosis and Improvement of Salina and Alkali Soils. Agricultural Handbook, 60, U.S.D.A.

Ülgen, N., \& Yurtsever, N. (1988). Türkiye Gübre ve Gübreleme Rehberi (3. Bask1). TC Tarım Orman Köy İşleri Bakanlığı, Köy Hizmetleri Genel Müdürlüğü, Toprak ve Gübre Araştırma Enstitüsü Müdürlüğü Yayınları, Genel Yayın, p.121.

Veiga, M. D., Reinert, D. J., \& Reichert, J. M. (2009). Aggregate stability as affected by short and longterm tillage systems and nutrient sources of a hapludox in southern brazil. Revista Brasileira De Ciência Do Solo, 33(4), 767-777.

Yılmaz, E., \& Alagöz, Z. (2005). Organik madde uygulamasının toprakta agregat oluşumu ve stabilitesine etkisi. Akdeniz Üniversitesi Ziraat Fakültesi Dergisi, 18(1), 131-138.

Yılmaz, E., Alagöz, Z., \& Öktüren, F. (2005). Toprakta agregat oluşumu ve stabilitesi. Selçuk Üniversitesi Ziraat Fakültesi Dergisi, 19(36), 78-86.

Zeng, Q., Darboux, F., Man, C., Zhu, Z., \& An, S. (2018). Soil aggregate stability under different rain conditions for three vegetation types on the loess plateau (china). Catena, 167, 276-283. 